\title{
Caracterização da Participação dos Usuários em Sessões Educacionais de Bate-papo
}

\author{
Edmilson Barcelos Rocha, Mariano Pimentel, Morganna Carmem Diniz
}

Departamento de Informática Aplicada - Universidade Federal do Estado do Rio de Janeiro (UNIRIO) - Rio de Janeiro - RJ - Brazil

\{edmilson.rocha, pimentel, morganna\}@uniriotec.br

\begin{abstract}
Graduation enrollment in the distance modality represented $23.5 \%$ of the total in 2014. There are more than 727 thousand students in this modality. Among the most used computing resources for the Distance Education are the forum and the chat. Synchronous media, such as chat, provide a relaxed environment, stimulate participation and a sense of belonging to the group. Knowing if 30 or 300 students can participate in a chat session is the research question that one wishes to answer. Through the scientific method Mathematical Modeling, three possible solutions were proposed to answer the question of research where the analytical model proved to be the most friendly solution.
\end{abstract}

Resumo. As matrículas na graduação na modalidade a distância representavam 23,5\% do total em 2014. São mais de 727 mil alunos nessa modalidade. Entre os meios computacionais mais utilizados para a EaD estão o fórum e o bate-papo. Meios síncronos de comunicação, como o bate-papo, proporcionam um ambiente descontraído, estimulam a participação e o sentimento de pertencimento ao grupo. Saber se em uma sessão de bate-papo podem participar 30 ou 300 alunos é a questão de pesquisa a que se deseja responder. Por meio do método científico Modelagem Matemática, foram propostas três soluções possíveis para responder à questão de pesquisa onde o modelo analítico apresentou-se como a solução de mais fácil utilização.

\section{Quantos alunos devem participar de um bate-papo educacional?}

Ultimamente tem-se percebido um grande avanço nos meios de comunicação mediados por computador. Seguindo esse avanço, a educação online vem se expandindo cada vez mais e alcançando um público cada vez maior. De acordo com o Censo e Educação Superior (INEP, 2014) a modalidade a distância representa $17,1 \%$ do total de matrículas da educação superior, atingindo 1,34 milhão em 2014. Muitos pesquisadores da educação online defendem o uso de meios de comunicação síncrono em conjunto com os assíncronos para uma maior participação (STALH 2009, HRASTINSK 2007, FUKS 2006). Entre os meios mais utilizados na educação online está o bate-papo.

Paulo Freire faz críticas à transmissão como sendo o modelo mais identificado como prática de ensino e menos habilitado a educar. Paulo Freire critica o que seria a "educação bancária", onde o educando recebe passivamente os conhecimentos, tornandose um depósito do educador (FREIRE, 1987). Para Marco Silva, a sala de aula deve ser interativa e para que haja interatividade é preciso garantir duas disposições basicamente: dialógica e intervenção (SILVA, 2014). A dialógica que associa emissão e recepção como polos antagônicos e complementares na co-criação da comunicação. A intervenção do 
VI Congresso Brasileiro de Informática na Educação (CBIE 2017)

Anais do XXVIII Simpósio Brasileiro de Informática na Educação (SBIE 2017)

usuário ou receptor no conteúdo da mensagem ou do programa abertos a manipulação e modificações.

O bate-papo se apresenta como um meio de comunicação que permite uma horizontalizarão da comunicação entre alunos e professor. No bate-papo há ausência de conteúdo expositivo, alta dialogicidade e descaracterização do professor como detentor do conhecimento e da palavra. A conversação informal, típica do bate-papo, possibilita o aluno perceber melhor o outro e perceber-se melhor como parte do grupo, proporciona um espaço para emoções que diminuem a sensação de impessoalidade e isolamento. Em cursos à distância, o uso do bate-papo contribui para manter os alunos motivados e engajados na disciplina, diminuindo a evasão (PIMENTEL et al., 2003). Quantos alunos devem participar de um bate-papo realizado no contexto educacional? Responder essa pergunta é importante, por exemplo, para planejar a carga-horária necessária para realizar uma sessão de bate-papo numa turma de um curso a distância. Saber se numa sessão de bate-papo podem participar ao mesmo tempo 100 ou apenas 10 alunos, tem um grande impacto financeiro no planejamento das atividades de um curso a distância.

Como cenário de estudo, o curso de Pedagogia do CEDERJ possui 400 alunos por turma. Caso o professor decida realizar sessões de bate-papo com a turma, quantas sessões de bate-papo seriam necessárias? Se a sessão tivesse a intenção apenas de transmitir conteúdo (educação bancária), então seria necessária apenas 1 sessão com 400 alunos. Se a intenção do professor for promover a construção de conhecimento em conjunto com os alunos (sala de aula interativa), então um melhor planejamento seria necessário. Nesse segundo caso, qual seria o número ideal de sessões de bate-papo? Poderiam ser feitas 10 sessões com 40 alunos, ou seriam melhor 20 sessões com 20 alunos cada? E por que não 40 sessões com 10 alunos já que o professor espera uma discussão com alta interatividade entre os participantes? Sabendo-se que em média uma sessão de bate-papo educacional tem duração de uma hora, seriam necessárias 40 horas extras para o professor conseguir realizar ao menos uma sessão de bate-papo com todos os alunos. Evidentemente essas horas extras tem um grande impacto financeiro para as instituições de ensino.

\section{Método de Pesquisa: Modelagem Matemática}

Para responder à pergunta de quantos devem participar de uma sessão de bate-papo educacional, foi escolhido o método de pesquisa Modelagem Matemática. Segundo Law e Kelton (2000), existem técnicas para usar o computador para imitar ou simular a operação de vários processos do mundo real e as duas mais conhecidas são a Modelagem a Simulação. Se a relação que compõe o modelo é simples o bastante, então é possível usar métodos matemáticos (álgebra, cálculo, teoria de probabilidade) para obter a informação exata da questão de interesse; isso é chamado solução analítica.

O processo do mundo real que esse trabalho se propõe a modelar é o da participação de alunos durante a realização de uma sessão de bate-papo. É pretendido modelar esse processo por meio da relação entre duas variáveis elencadas como as principais para o problema: quantidade de participantes $(p)$ e quantidade de mensagens produzidas por participante $(m)$. Além das variáveis, são considerados os pressupostos de que existe relação entre essas duas variáveis e que essa relação é inversamente proporcional, ou seja, quanto maior o número de participantes menor a produção de mensagens. 
VI Congresso Brasileiro de Informática na Educação (CBIE 2017)

Anais do XXVIII Simpósio Brasileiro de Informática na Educação (SBIE 2017)

Arenales e colaboradores (2007) desenvolveram um processo para realizar uma pesquisa científica com método modelagem matemática. Esse processo é composto por quatro etapas e consiste de um processo iterativo, ou seja, pode ser realizado repetidas vezes até alcançar uma solução satisfatória para o problema. No diagrama apresentado na Figura 1 e extraído de Arelanes et al. (2007, pág 4), é ilustrado o processo simplificado da abordagem de solução de problema utilizando a Modelagem Matemática.

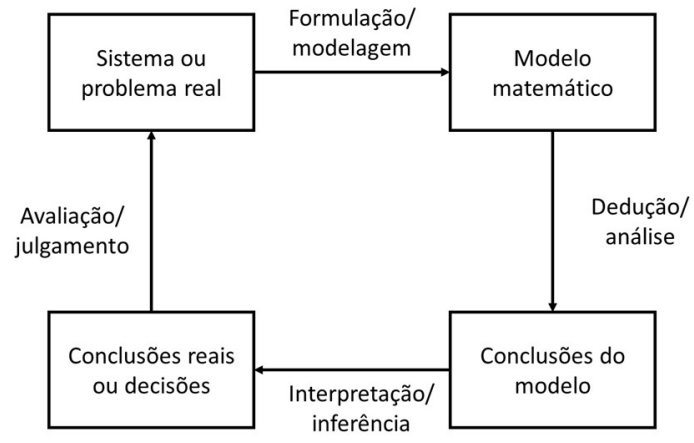

Figura 1. Processo de Modelagem (Arenales et al., 2007, pag. 4)

Essa abordagem de resolução de um problema envolve várias fases a serem descritas em seguida. Conforme apresentado anteriormente, procura-se a relação entre as variáveis $p$ e $m$ identificadas a partir do problema da imprecisão de quantos devem participar de uma sessão de bate-papo. Para essa modelagem tem-se alguns pressupostos:

1. A produção de mensagens tende a aumentar com o aumento do tamanho do grupo até atingir um ponto de produção máxima (em torno de 5 ou 6 participantes)

2. A produção de mensagens tem uma relação inversa com o tamanho do grupo a partir do ponto máximo

3. A produção de mensagens tende a zero com grupos grande, mas nunca é negativa

4. A produção de mensagens depende do contexto do bate-papo

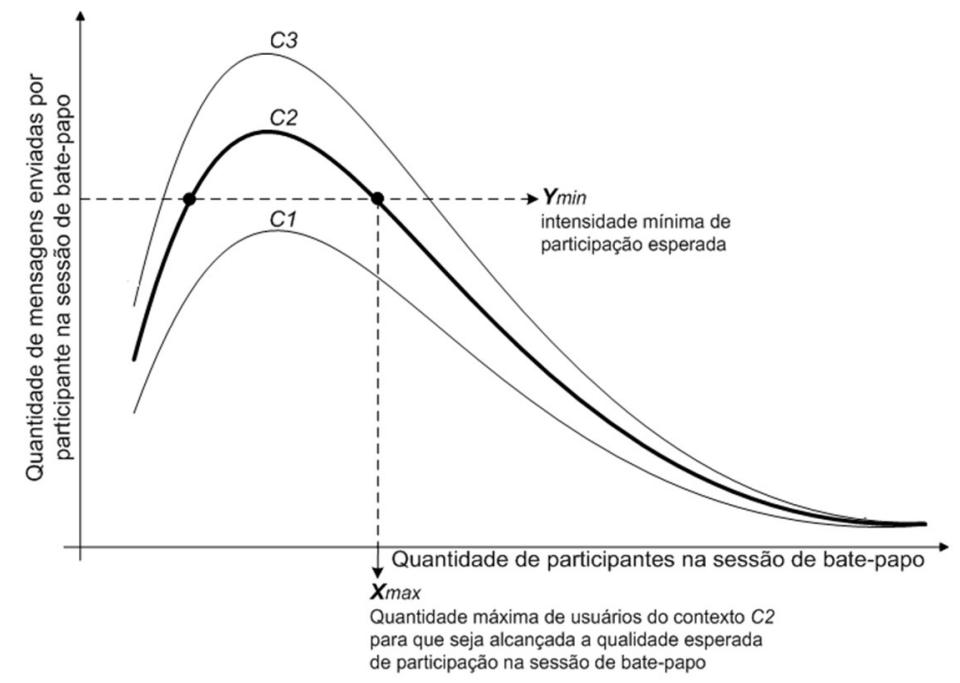

Figura 2 Modelo Conceitual da Participação em Bate-papo Educacional

Nessa fase são definidos o escopo do problema em estudo, as decisões de interesse, os objetivos envolvidos, e o modelo conceitual do problema. Segundo Arenales e colaboradores (2007), o modelo conceitual deve descrever as alternativas de decisões e 
as limitações sob as quais o sistema modelado funciona. $\mathrm{O}$ modelo conceitual parte de pressuposto que os alunos realizam algumas atividades elementares, como leitura e escrita de mensagens, durante a sessão de bate-papo. Medir essas atividades é importante para caracterizar o contexto da turma. Na Figura 2, é ilustrado o modelo conceitual. Esperase que, durante uma sessão de bate-papo educacional, o aluno consiga ler todas as mensagens e produzir uma quantidade $\mathbf{Y}_{\text {min }}$ de respostas ou contribuições a discussão. Conforme o contexto em que a sessão de bate-papo esteja ocorrendo, o modelo estimará uma quantidade $\mathbf{X}_{\max }$ de participantes em que a produção esperada de mensagem seja garantida. Contextos diferentes produzirão resultados diferentes, ou seja, uma sessão de bate-papo de uma turma de graduação discutindo uma assunto complexo não terá as mesmas características que uma turma voltada para um público idoso onde seja debatido um tema com menor complexidade. Gênero, idade e nível de instrução já foram investigados em pesquisas sobre participação online e evidenciados como fatores influenciadores da participação (HRASTINSKI, 2007, pág 106).

As outras fases do método de modelagem segundo Arenales (2007) são: Formulação e Modelagem, onde as informações coletadas na primeira fase são usadas para desenvolver um modelo matemático do problema por meio de relações matemáticas ou lógicas de simulação. Dedução e Análise, onde são utilizados métodos de solução e algoritmos para resolver o modelo construído na segunda fase. Esses algoritmos podem ser conhecidos da literatura ou desenvolvidos especificamente para tratar o modelo da segunda fase. Interpretação e Inferência, onde é verificado se o modelo proposto representa apropriadamente o problema, ou seja, se o modelo descreve adequadamente o comportamento do sistema real. Um método comum para verificar a validade de um modelo é comparar seus resultados com dados históricos do problema. Avaliação e Julgamento, onde a preocupação é com a implementação da solução na prática da empresa ou organização traduzindo os resultados do modelo em conclusões ou decisões.

\section{Modelo Analítico}

Conforme apresentado anteriormente, o objetivo da pesquisa é caracterizar matematicamente a participação dos alunos em sessões de bate-papo educacional a fim de estimar a produção de mensagens em função da quantidade de participantes. Para isso, foram identificadas as duas variáveis de interesse, $p$ quantidade de participantes e $m$ produção de mensagens por participante, e a relação entre essas duas variáveis. Além disso, identificou-se duas atividades do participante: leitura e escrita de mensagens. Com essas informações e pressupostos, serão apresentados dois cenários de aplicação.

\subsection{Cenário 1: Escrevem e Leem o tempo todo}

No primeiro cenário, apresenta-se uma sessão de bate-papo em que os participantes permanecem escrevendo e lendo mensagens o tempo todo, sem ficarem ociosos. Para esse cenário, espera-se uma produção de mensagem por participante $(m)$ muito elevada. Se uma sessão de bate-papo é realizada durante um intervalo de tempo que pode variar de alguns minutos para algumas horas, então a duração do bate-papo também influencia a produção média de mensagens por participante, pois o participante tende a produzir muito mais mensagens em uma sessão de 1 hora do que em uma sessão de apenas 10 ou 20 minutos. Para o tempo da sessão de bate-papo define-se a variável $T_{s}$. Com isso, tem-se a primeira abstração com relação ao bate-papo conforme apresentado na Equação 1.

$$
T_{S}=T_{\text {Escrevendo }}+T_{\text {Lendo }}
$$


Sabe-se que cada participante escreve mensagens de uma maneira particular e possui um tempo de escrita próprio. Em um grupo de alunos, é de interesse saber o tempo médio de escrita de mensagens. Sabe-se também que o tempo de escrita possui uma forte correlação com o tamanho da mensagem. Define-se então $\bar{T}_{e}$, como o tempo médio de escrita de todos os alunos do grupo, para mensagens que possuam um tamanho de $c$ caracteres, que é a média de caracteres das mensagens produzidas durante uma sessão de bate-papo. Durante uma sessão de bate-papo em que cada participante produz em média $m$ mensagens, o tempo total escrevendo é dado pela Equação 2.

$$
T_{\text {Escrevendo }}=m * \bar{T}_{e}
$$

Além de escrever mensagens o participante também lê as mensagens enviadas pelos outros participantes do grupo do bate-papo. Assume-se que o participante não lê a própria mensagem que envia. Isso significa que um participante lê as mensagens de $p-1$ participantes da sessão de bate-papo. O tempo de leitura de mensagens também é fortemente correlacionado com o tamanho da mensagem. Para o tempo médio de leitura de mensagens de $c$ caracteres define-se a variável $\bar{T}_{l}$. O tempo total que o participante permanece lendo mensagens durante o bate-papo é dado pela Equação 3 .

$$
T_{\text {Lendo }}=m *(p-1) * \bar{T}_{l}
$$

Nesse cenário, em que o participante permanece lendo e escrevendo mensagens durante todo o tempo, basta substituir os termos das Equações 2 e 3 na Equação1 para se obter a média de mensagens produzidas por participante conforme a Equação 4.

$$
\begin{gathered}
T_{s}=\left(m * \bar{T}_{e}\right)+\left(m *(p-1) * \bar{T}_{l}\right) \\
\left.T_{s}=m\left(\bar{T}_{e}+(p-1) * \bar{T}_{l}\right)\right) \\
m=\frac{T_{s}}{\bar{T}_{e}+\left((p-1) * \bar{T}_{l}\right)}
\end{gathered}
$$

Para exemplificar a aplicação da Equação 4, são usados como parâmetros de entrada da equação os tempos obtidos de uma turma de educação online ministrada durante o semestre 2007.1 na cidade do Rio de Janeiro (FUKS et al., 2002) onde as mensagens produzidas tiveram uma média de 94,1 caracteres. Para essa turma tem-se: $T_{S}$ $=60$ minutos; $\bar{T}_{e}=0,44$ minutos; $\bar{T}_{l}=0,08$ minutos.

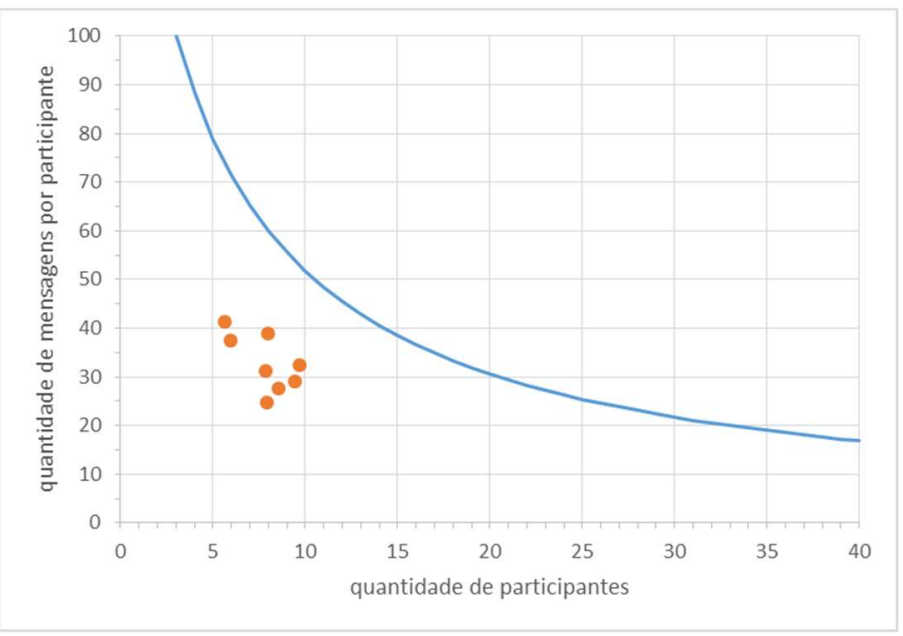

Figura 3 Curva de participação para equação de produção máxima 
Na Figura 3, é apresentada a curva resultante da Equação 4 para o intervalo $p$ igual a $[3,40]=\{p \in \mathbb{R} \mid 3 \leq p \leq 40\}$. O gráfico apresenta a curva de participação, produção de mensagens, em função da quantidade de participantes. Os oito pontos abaixo da curva representam cada uma das oito sessões de bate-papo com duração de 60 minutos realizadas na turma 2007.1. Observa-se que a quantidade de participantes da turma 2007.1 ficou entre 5 e 10. Para esse intervalo de participantes, a equação estimou uma produção entre 50 e 78 mensagens, mas os dados reais mostram uma produção entre 25 e 42 mensagens. Os valores estimados são muito superiores aos observados na turma real conforme já esperado. Sabe-se que os participantes do bate-papo não permanecem o tempo todo lendo e escrevendo mensagens. Eles também necessitam de um tempo para refletir sobre as mensagens lidas e elaborar uma resposta ou contribuição para a discussão. Com isso, apresenta-se o Cenário 2.

\subsection{Cenário 2: Escreve, Aguarda Resposta e Lê}

O participante não escreve mensagens aleatoriamente. Ele espera que um outro participante envie alguma consideração sobre a sua mensagem. Com isso, forma-se um ciclo em que o participante aguarda uma mensagem para iniciar a leitura e a escrita de uma nova mensagem. O tempo médio que o participante aguarda por uma mensagem é representado por $\overline{T_{A R}}$ e está diretamente relacionado com $\bar{T}_{e}$ e $\bar{T}_{l}$ da turma.

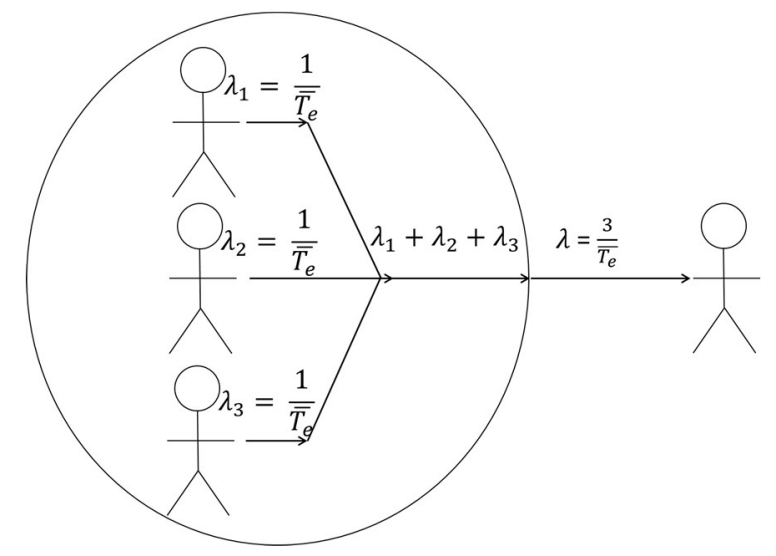

Figura 4 Representação do tempo de resposta para diferentes grupos

Se um participante demora $\bar{T}_{e}$ para escrever uma mensagem, então esse participante produz mensagens a uma taxa de $1 / \bar{T}_{e}$. Com um grupo de 4 participantes, um dos participantes receberá mensagens dos $p-1$ participantes a uma taxa de chegada igual ao somatório das taxas de produção de mensagens dos $p-1$ participantes. Em Teoria de Filas, representamos taxa de chegada por meio da letra grega $\lambda$. Então, a taxa de chegada $\lambda$ na fila de leitura do participante será igual ao somatório da taxa de produção de mensagens dos $p-1$ participantes, que é igual a $3 \lambda$. Esse comportamento é ilustrado na Figura 4.

Quanto mais participantes houver na sessão de bate-papo, menos o participante ficará aguardando mensagem. Ou seja, quanto maior $p$, menor $\overline{T_{A R}}$. Deste modo, para $\overline{T_{A R}}$ temse a relação representada pela Equação 5.

$$
\overline{T_{A R}}=\frac{1}{\lambda}=\frac{\overline{T_{e}}}{p-1}
$$


VI Congresso Brasileiro de Informática na Educação (CBIE 2017)

Anais do XXVIII Simpósio Brasileiro de Informática na Educação (SBIE 2017)

Com esse novo parâmetro, evolui-se a Equação 4 incrementando o termo da Equação 5. Com isso tem-se a Equação 6.

$$
\begin{gathered}
T_{s}=\left(m * \overline{T_{e}}\right)+\left(\mathrm{m} * \overline{T_{A R}}\right)+\left(m *(p-1) * \bar{T}_{l}\right) \\
T_{s}=m *\left(\overline{T_{e}}+\overline{T_{A R}}+\left((p-1) * \bar{T}_{l}\right)\right) \\
m=\frac{T_{s}}{\overline{T_{e}+\overline{T_{A R}}+\left((p-1) * \bar{T}_{l}\right)}} \\
m=\frac{T_{s}}{\overline{T_{e}}+\left(\frac{\bar{T}_{e}}{p-1}\right)+\left((p-1) * \bar{T}_{l}\right)}
\end{gathered}
$$

De forma a exemplificar a aplicação da Equação 6, toma-se novamente como parâmetros de entrada da equação os tempos obtidos da turma de educação online 2007.1 onde as mensagens produzidas tiveram uma média de 94,1 caracteres; $T_{S}=60$ minutos; $\overline{T_{e}}=0,44$ minutos; $\bar{T}_{l}=0,08$ minutos. Na Figura 5, é apresentada a curva de participação obtida pela Equação 6 para o intervalo $p$ igual a $[3,40]=\{p \in \mathbb{R} \mid 3 \leq p \leq 40\}$.

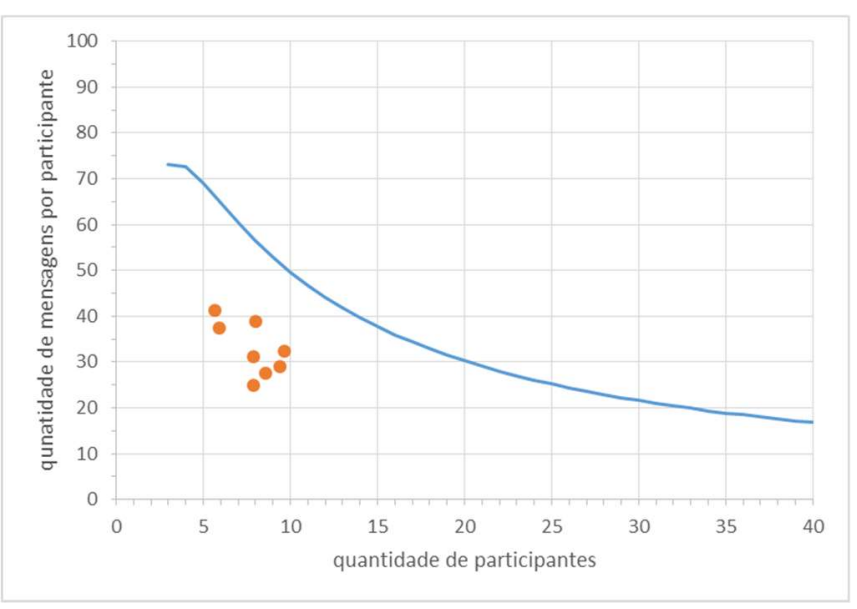

Figura 5 Curva obtida pela Equação 6

Observa-se na Figura 5, que a produção de mensagens da turma 2007.1 para o intervalo de participantes entre 5 e 10 foi entre 25 e 42 mensagens. Os resultados estimados pela Equação 6 para o mesmo intervalo de participantes foi entre 50 e 69 mensagens. Esses resultados ficaram abaixo dos 50 e 78 estimados pela Equação 4 de produção máxima, porém ainda ficaram muito acima dos pontos reais observados. Para aproximar mais a curva estimada dos dados observados é necessário a utilização de um fator de ajuste que será representado pela constante $\mathrm{K}$. Essa constante se refere ao contexto em que se realiza a sessão de bate-papo conforme apresentado na Seção 2. A Equação 6 com a aplicação do fator de ajuste é representada na forma da Equação 7.

$$
m=\frac{T_{s}}{\bar{T}_{e}+\left(\frac{\bar{T}_{e}}{p-1}\right)+\left((p-1) * \bar{T}_{l}\right)+\mathrm{k}}
$$

Para exemplificar a aplicação do fator de ajuste, considera-se os valores de $\mathrm{k}=0,4$; 0,$8 ; 1,2$. Na Figura 6, são apresentadas as curvas de participação com fatores de ajuste. 
VI Congresso Brasileiro de Informática na Educação (CBIE 2017)

Anais do XXVIII Simpósio Brasileiro de Informática na Educação (SBIE 2017)

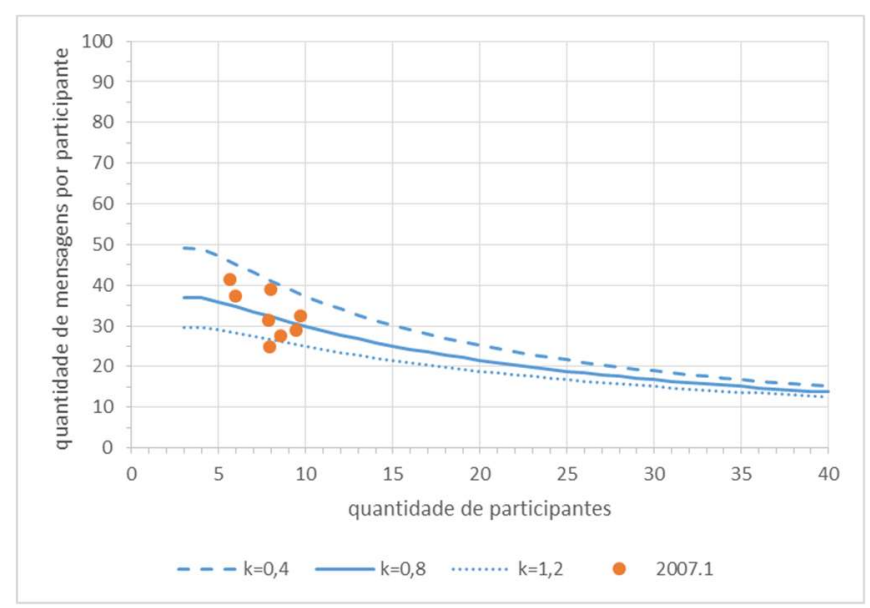

Figura 6 Representação das curvas de participação com fator de ajuste $k$

Verifica-se que a curva com fator de ajuste $\mathrm{k}=0,8$ é a que mais se aproxima dos dados reais. Visualmente é uma curva que representa satisfatoriamente os dados da turma 2007.1, porém deve-se questionar se outras curvas representariam melhor os dados reais.

\subsection{Validação da Equação - Comparação com a Tendência Linear}

Uma das formas de avaliar a qualidade do ajuste do modelo é através do coeficiente de determinação ou simplesmente $\mathbf{R}^{\mathbf{2}}$. Este coeficiente indica quanto o modelo foi capaz de explicar os dados coletados. Na Figura 7, são apresentadas a curva de participação obtida pela Equação 7 e a linha de tendência linear com o valor de $\mathrm{R}^{2}$.

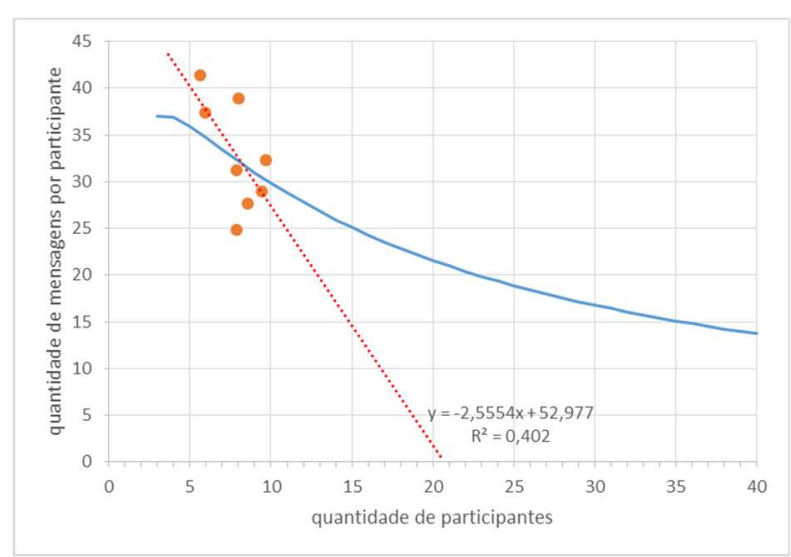

Figura 7 Comparação com a tendência linear para a turma 2007.1

O R2 é, portanto, uma medida descritiva da qualidade do ajuste obtido e pode ser calculado pelo Microsoft ${ }^{\circledR}$ Excel ${ }^{\circledR}$ pela função RQUAD passando-se como argumentos os valores observados e valores estimados. Na Tabela 1 , verifica-se os valores estimados para $m$ e os valores obtidos pela Equação 7 com fator de ajuste $\mathrm{k}=0,8$. Para a turma 2007.1, o $\mathrm{R}^{2}$ encontrado foi de 0,40 o que é o mesmo $\mathrm{R}^{2}=0,402$ encontrado para a função linear.

Tabela 1 Coeficiente de determinação dos dados observados da turma 2007.1

\begin{tabular}{|c|c|c|c|c|c|c|c|c|}
\hline & debate 1 & debate 2 & debate 3 & debate 4 & debate 5 & debate 6 & debate 7 & debate 8 \\
\hline$p$ & 7,9 & 8,6 & 9,7 & 9,4 & 5,9 & 8 & 7,9 & 5,6 \\
\hline$m$ Turma 2007.1 & 24,8 & 27,6 & 32,3 & 29,0 & 37,4 & 38,9 & 31,3 & 41,8 \\
\hline$m$ Equação 6 & 32,3 & 31,5 & 30,2 & 30,5 & 34,8 & 32,2 & 32,4 & 35,2 \\
\hline
\end{tabular}


VI Congresso Brasileiro de Informática na Educação (CBIE 2017)

Anais do XXVIII Simpósio Brasileiro de Informática na Educação (SBIE 2017)

Para o contexto da turma 2007.1, verificou-se que o modelo construído por meio da Equação 7 apresentou o mesmo ajuste aos dados observados que a função linear. $\mathrm{R}^{2}=0,4$. Na Figura 8 , são apresentadas curvas de participação de outras 4 turmas. Para essas turmas, foram utilizados os seguintes fatores de ajuste: 2006.1, $\mathrm{k}=1,3 ; 2006.2$, $\mathrm{k}=0,4 ; 2007.2, \mathrm{k}=0,8 ; 2008.1, \mathrm{k}=0,5$. Os coeficientes de determinação calculados pela equação para essas curvas foram: 2006.1, $\mathrm{R}^{2}=0,571 ; 2006.2, \mathrm{R}^{2}=0,819 ; 2007.2$, $\mathrm{R}^{2}=0,752 ; 2008.1, \mathrm{R}^{2}=0,009$. Para essas turmas, o $\mathrm{R}^{2}$ calculado com base na equação também ficou muito próximo do $\mathrm{R}^{2}$ da função linear.

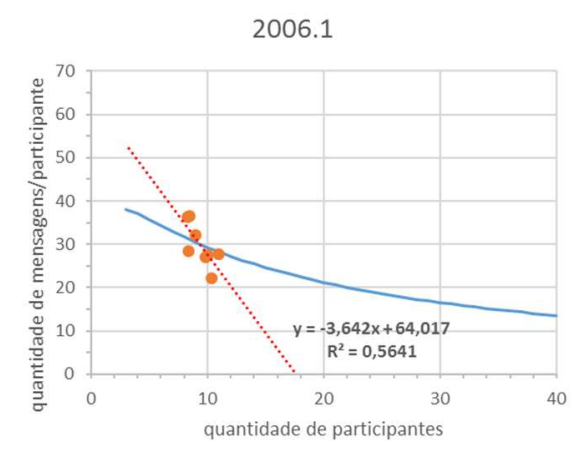

2007.2

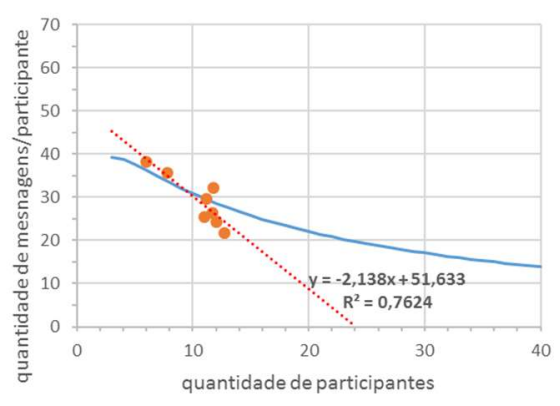

2006.2

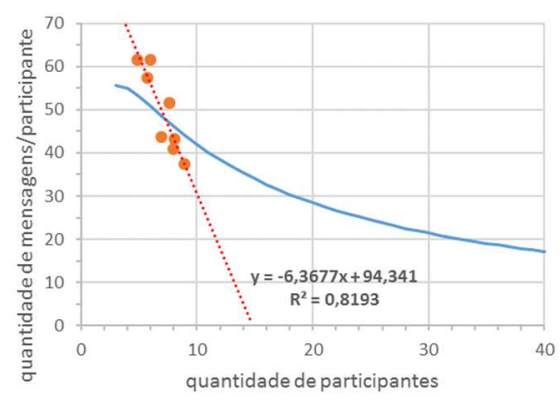

2008.1

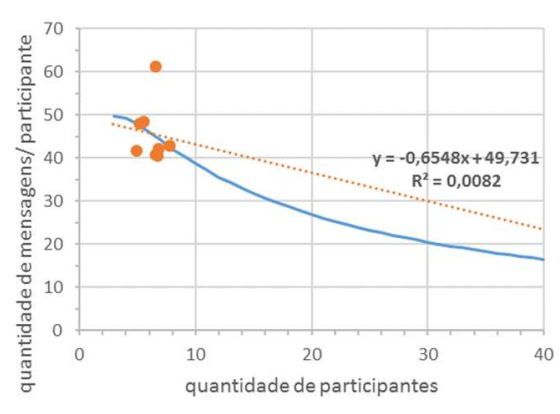

Figura 8 Curvas de participação e comparação com a tendência linear

Conforme apresentado na Figura 8, os dados reais observados ficam em torno de 10 participantes. Deseja-se extrapolar esse valor a fim de obter estimativas para grupos de tamanhos maiores como 30 participantes. Por meio de uma análise visual, percebe-se que a linha de tendência linear cai muito rápido a mediada que se aumenta o número de participantes. Com exemplo a turma 2006.2, que pela tendência linear, zera a produção de mensagens para 15 participantes enquanto que pela equação matemática, estimasse uma produção de 34 mensagens por participante. Embora a função linear e a equação obtenham coeficientes de determinação muito próximos, as estimativas produzidas pela equação para grupos maiores são mais próximas do real.

\section{Conclusão}

Conforme apresentado no artigo, a Solução Analítica (Equação 7) apresenta-se como uma solução opcional ao modelo estocástico baseado em Teoria de Filas apresentado em Rocha e colaboradores (2015) para o problema de estimar quantos devem participar de um bate-papo educacional. Verificou-se que os métodos para a obtenção dos parâmetros de entrada para a equação (tempo médio de leitura e tempo médio de escrita) são viáveis de serem implementados em sistemas de bate-papo e podem ser usados em uma sessão 
inicial de diagnóstico da turma em que se deseja aplicar o modelo. Verificou-se também que a equação matemática produz estimativas confiáveis e é de aplicação direta. A equação também pode ser implementada em sistemas de bate-papo ou em site da internet para ser manipulada por professores e gestores de educação a distância.

Como limitações da pesquisa destaca-se principalmente a dificuldade de modelar o comportamento humano por sua imprevisibilidade. Sabe-se que a participação é influenciada por diversos fatores e varia de pessoa a pessoa. Como trabalho futuro, pretende-se caracterizar melhor processos em que o participante não está lendo ou escrevendo mensagens como tempo para assimilação da mensagem lida, tempo de reflexão e preparação de uma mensagem de resposta ou contribuição. A principal contribuição do artigo é fornecer um instrumento de manuseio acessível para demostrar de forma clara e concreta que não é possível realizar sessões de bate-papo educacional com um número muito grade de alunos. Conforme cenário do CEDERJ apresentado na Seção 1, não seria possível a realização de uma única sessão de bate-papo com 400 participantes. A turma deveria ser dividida em grupos menores para que fossem realizadas sessões em que a participação pudesse ser aceitável do ponto de vista do professor.

\section{Referências}

ABED, Associação Brasileira de Educação a Distância. Censo EAD.BR. Disponível em: $<$ http://www.abed.org.br/censoead2013/CENSO_EAD_2013_PORTUGUES.pdf $>$.

ARENAlES, M., ARMENTANO, V., MORABITO, R., \& YANASSE, H. (2007). Pesquisa operacional: para cursos de engenharia. Elsevier Brasil.

INEP-BRASIL. Apresentação Estatísticas INEP 2014. . [S.1.]: Instituto Nacional de Estudos e Pesquisas Educacionais Anísio Teixeira (INEP).

FUKS, Hugo; GEROSA, Marco Aurelio; DE LUCENA, Carlos Jose Pereira. The development and application of distance learning courses on the internet. Open Learning, v. 17, n. 1, p. 23-38, 2002.

FUKS, Hugo; PIMENTEL, Mariano; DE LUCENA, Carlos José Pereira. RU-Typing-2$\mathrm{Me}$ ? Evolving a chat tool to increase understanding in learning activities. International Journal of Computer-Supported Collaborative Learning, v. 1, n. 1, p. 117-142, 2006.

FREIRE, Paulo. Pedagogia do Oprimido. Rio de Janeiro: Paz e Terra, 1987. _. Educação e mudança, v. 18, 1995.

HRASTINSKI, Stefan. Participating in synchronous online education. KFS AB, 2007. Disponível em < http://lup.lub.lu.se/search/ws/files/4623381/600490.pdf>.

LAW Averill, M.; David, KELTON W. Simulation modeling and analysis. Mc-Graw Hill, 2000.

PIMENTEL, Mariano Gomes; FUKS, Hugo; DE LUCENA, Carlos José Pereira. Debati, debati... aprendi? In: Anais do Workshop de Informática na Escola. 2003. p. 61-72.

ROCHA, Edmilson Barcelos; PIMENTEL, Mariano; DINIZ, Morganna Carmem. Quantidade de Participantes em Bate-papo Educacional: um Modelo Baseado em Teoria de Filas. Revista Brasileira de Informática na Educação, 2015.

SILVA, Marco. Sala de Aula Interativa. 7a. Edição ed. Rio de Janeiro: Loyola, 2014.

STAHL, G. Studying Virtual Math Teams. New York, NY: Springer, 2009. 